\title{
ALTERED IMAGES: THE RELATIONS BETWEEN DESIGN REPRESENTATIONS AND DESIGN PRACTICE
}

\author{
Ms Susan Keller, Dr Ross Smith \\ Deakin University \\ Dr Steve Howard, Dr Jennie Carroll \\ University of Melbourne \\ School of Information Systems \\ Deakin University \\ Melbourne, Victoria \\ Email: Susan.Keller@deakin.edu.au, Ross.Smith@deakin.edu.au \\ Department of Information Systems \\ University of Melbourne \\ Melbourne, Victoria \\ Email: showard@unimelb.edu.au,jCarroll@staff.dis.unimelb.edu.au
}

\begin{abstract}
As information systems move out of the office into the wider world and are merged with mobile appliances, buildings and even clothing, the representations traditionally used in any one discipline may not be adequate for understanding these new domains. Design representations are 'ways of seeing and not seeing'. Despite the central role representations play in design, the information systems design community has little understanding of the relation, ideal or actual, between design practice and design representation. This paper reports on an extensive design case study that aims at increasing understanding of the nature and affordances of representations in the design process and argues for the need for information systems as a discipline to open up discussion of the design representations that may be required to effectively design systems that mix traditional IS with disciplines such as industrial design, architecture and fashion design.
\end{abstract}

Keywords Design representations, design process, affordances, case study, industrial design

\section{INTRODUCTION}

Advances in technology are leading information systems out of the office and into domains such as mobile appliances, buildings and even clothing. These new domains present design challenges which the current repertoire of design representations may not be able to adequately represent. Already the boundaries between work/organisational, social and personal activities are becoming blurred: consider for instance the impact of mobile technologies (Carroll et al. 2001). These changes mean we will increasingly place importance on cross-activity and cross-domain design in IS and this will require an expanded mindset and a richer toolkit of representations.

Design, whether in IS, urban planning, industrial design or architecture, requires designers to create and to give form to ideas through representations. Representation has a profound influence on design (Hevner et al. 2004) and it is the quality of the representational artefacts that largely determines the degree to which we can reflect on our designs (Suchman 1994). Yet compared to other design disciplines IS has an impoverished set of design representations, especially design representations that allow reasoning of the design as a whole (Stolterman 1999) and the information systems design community has little understanding of the relation, ideal or actual, between design practice and design representation.

We argue that different design representations facilitate some designers' activities and constrain others: the affordances, or material properties, of design representations may influence the particular representation choices designers make. Further, we conjecture that examination of design representations across different design disciplines may provide theoretical understandings that could: enable the development of new representations that allow better design of mobile, wearable, tangible 
and ubiquitous computing systems; enhance cross-discipline communication; and provide a basis for the development of design tools to support design in these new contexts.

The paper begins with a discussion of design and design representations then moves on to discuss the research approach and the case study findings from a first case which was undertaken at an industrial design site. Such a site was chosen as a starting point because of the rich selection of design artefacts employed in a short life-cycle development process - features it is argued that might subsequently inform an enhanced understanding of IS design. The paper presents several different ways of examining design representations. Different representations allow consideration of certain aspects or views of the design; the views, identified in the industrial design case study are outlined. Next a high-level description of the design process is presented and mapped against the views. This allows us to describe some of the affordances of particular design representations. Finally, a brief reflection on the implications of the case study to the future world of designing ubiquitous IS applications is presented.

\section{DESIGN AND DESIGN REPRESENTATIONS}

There are many ways design can be conceptualised, but a useful one for thinking about design representations is offered by Rosenman and Gero (1998). They contend that as humans we exist in a physical world which gives rise to certain needs (for example shelter, warmth) but we also exist in a socio-cultural world of our own making. This socio-cultural world also gives rise to various needs and desires. The artefacts that are created as a result of the needs arising in these two worlds form the techno-physical world. Design can thus be seen as a human endeavour that starts with an idea conceived to satisfy some human need or desire and ends with a syntactical description of an artefact that when realised is intended to satisfy that need: it proceeds from "a human socio-cultural environment to an artefact techno-physical environment" (Rosenman and Gero, 1998).

Design representations are an intrinsic part of design (Perry and Sanderson 1998). In fact some researchers define design as the production of design artefacts (Dym 1994), (Galle 1999). Design representations allow reasoning about design issues and some authors (Dym 1994; Simon 1996) argue that problem solving in design is basically a matter of finding a representation that makes the solution obvious. Consider for instance, Chen's (1976) development of the entity-relationship model. This representation, of the semantics of data, profoundly influenced how we reason about data in information systems (Hevner et al. 2004).

Design representations can be defined as any 'perceptible expression of a design idea, proposal or fact' (Saddler 2001). This definition includes conversations, sketches, scenarios, storyboards and schematic representations.

Brereton (2004) categorises representations in terms of: whether they exist only in the mind (internal) or are expressed in the world (external), whether they are transient, such as utterances, or durable, and whether they are generated during the process or appropriated ready-made to assist with the design.

Saddler (2001) offers a fine-grained analysis of the role of design representations in design including such purposes as 'making ideas manipulable', 'summarising design decisions' and 'forcing things into the open'. These are not incompatible with the two roles Galle (1999) offers: that of communication and exploration. Galle (1999) includes 'self-communication' to cover those instances when the designer uses design representations to think through design issues. The social role of design representations is summed up by Perry and Sanderson (1998): design representations "are the foci of much of the social interaction, as contested symbols, objectifications of temporary agreements, and symbolic representations of potential productions."

Design representations have been studied in different discrete domains including information 
systems (see for example (Faro and Giordano 1999; Kyng 1995; Perry and Sanderson 1998; Stolterman 1999)but there appears to be little research on the role of design representations in emerging contexts where the boundary between IS and other types of design is being blurred. The research presented in this paper is a first step in addressing this gap.

\section{RESEARCH DESIGN}

The present research seeks to build an enhanced understanding of the nature and affordances of representations in the design process and to argue the need for IS as a discipline to open up discussion of the design representations that might be required to effectively design systems for the next generation of ubiquitous IS applications mixing IS with disciplines such as industrial design.

An interpretive research approach has been selected because the project aims at building understanding of the role of design representations during the design process and Klein and Myer (1999) suggest that interpretive research facilitates understanding 'human thought and action in social and organizational contexts'.

A case study method has been selected because of the exploratory nature of the research (Marshall and Rossman 1995). A series of case studies; starting first in the world of industrial design, but then migrating to the world of IS design, including designing for the world of ubiquitous IS applications, is planned.

The initial case study, which is the focus of this paper, was conducted at an industrial design company we shall call InDesigns. An industrial design company was chosen because of the rich selection of design artefacts evident in their process, the emphasis on creativity in design and the short life-cycle of the development process. The fieldwork took place over a period of six months and involved the investigator spending at least three hours each week at the company and also one two week period full time. The weekly visits allowed observation of a variety of projects at different stages. This provided a good understanding of the types of representations produced and their uses. During the full-time period at the company one project was followed from inception, allowing a more complete understanding of the overall process.

Data collection involved participant observation supplemented with semi-structured interviews, and the examination of archived documents and artefacts used by designers. Most of the interviews were taped as were many design team meetings.

The data were analysed using standard inductive techniques such as coding and thematic analysis (Babbie 2001; Miles and Huberman 1994). An initial conceptual framework, developed from the literature, was used to focus data collection and to provide initial categories for coding. These early categories were replaced with categories that arose from analysis of the data.

Finally, the concepts, derived from the analysis, were presented to the participants at the end of the case study period. Two of the most experienced designers in the organisation attended and gave their support to the conceptualisations.

\section{FINDINGS FROM THE CASE STUDY}

In this section, the basic design process at InDesigns is outlined. Then the physical design representations that are created during the process are described. The conceptualisations arising from the analysis of the data are then presented, followed by a brief concluding reflection on some of the possible implications of the case study to the future world of IS applications design. 


\section{Organisational Background}

InDesigns employs between three to six designers depending on work-load and it specialises in the design of electronic devices such as personal digital assistants, electronic monitoring devices and small kitchen appliances. InDesigns typically has up to six projects going at any one time and it also manages the manufacturing side of the product design process. During this study six different designers were studied. Two of these designers had less than two years experience and the other four had a minimum of eight years experience.

\section{Design Process at InDesigns}

InDesigns employs a process which they conceptualise as having three main phases: concept development; design development; and engineering design. During concept development the client's idea is explored and different designs are put forward for discussion. During design development the selected design elements are further elaborated with the focus moving to the component parts of the product and how they will fit together. Finally, during engineering design the detail design is further refined using a CAD engineering package. At the end of this stage an exact prototype of the product can be built from the CAD data. As in all design the process is not linear but involves much iteration, however the process moves the design from the socio-cultural to the techno-physical; from consideration of how the client idea can be designed to satisfy some human need or desire, to the various aspects of the design which will eventually enable a syntactic description of the artefact to emerge. The use of design representations is central to this process.

\section{Design Representations Used}

Table 1 below summarises some of the external, durable and self-generated (Brereton 2004) design representations that have been observed in use during the design process. This is not to underplay the importance of the more transient representations such as conversations and gestures. The table characterises the observed design representations in terms of form (the physical form the representation takes), description (description of the content of the representation) and role/actors (the role the representation plays in the design process and who uses it).

Table 1: The observed form, description, role and actors of industrial design representations.

\begin{tabular}{|l|l|l|}
\hline Form & Description & Role/Actors \\
\hline $\begin{array}{l}\text { Brief (Textual } \\
\text { descriptions) }\end{array}$ & High level product description & $\begin{array}{l}\text { Making ideas and intentions tangible. } \\
\text { Client and designer negotiate. }\end{array}$ \\
\hline $\begin{array}{l}\text { Emails (Textual } \\
\text { descriptions plus } \\
\text { sketches) }\end{array}$ & $\begin{array}{l}\text { Information discussed verbally often } \\
\text { accompanied by sketches }\end{array}$ & $\begin{array}{l}\text { Summarising knowledge, confirming } \\
\text { details, making less ambiguous. } \\
\text { Designers send to other } \\
\text { stakeholders.. }\end{array}$ \\
\hline $\begin{array}{l}\text { Concept (presentation) } \\
\text { boards }\end{array}$ & $\begin{array}{l}\text { Attractive but vague pictures of } \\
\text { various designs of the product }\end{array}$ & $\begin{array}{l}\text { Summarising designers' ideas. } \\
\text { Designers present to client. }\end{array}$ \\
\hline $\begin{array}{l}\text { Sketches - used for } \\
\text { communication }\end{array}$ & $\begin{array}{l}\text { Design elements } \\
\text { Whole designs }\end{array}$ & $\begin{array}{l}\text { Communicate with other designers, } \\
\text { clients, or manufacturers. }\end{array}$ \\
\hline
\end{tabular}




\begin{tabular}{|c|c|c|}
\hline Form & Description & Role/Actors \\
\hline $\begin{array}{l}\text { Sketches - used for } \\
\text { designer's thinking tasks. }\end{array}$ & $\begin{array}{l}\text { Design features such as where an } \\
\text { antenna will sit. }\end{array}$ & $\begin{array}{l}\text { Allow designer to work through idea } \\
\text { and problem solve visually. Also } \\
\text { allows for idea generation whether } \\
\text { feature, theme or style. }\end{array}$ \\
\hline Electronics printout & $\begin{array}{l}\text { Size and shape of internal electronics } \\
\text { printed out from CAD in } 1: 1 \text { scale so } \\
\text { form can be drawn around it. }\end{array}$ & $\begin{array}{l}\text { Designer use to understand one } \\
\text { constraint on the form. }\end{array}$ \\
\hline 2D drawing & $\begin{array}{l}\text { Technical drawings with } \\
\text { measurements of dimensions } \\
\text { product, wall thicknesses, clearances } \\
\text { etc }\end{array}$ & $\begin{array}{l}\text { Allow designers to check } \\
\text { measurements }\end{array}$ \\
\hline 2D image & Attractive picture of product & $\begin{array}{l}\text { Facilitate requirements elicitation. } \\
\text { Designer presents to client. } \\
\text { Allow visual, symbolic and } \\
\text { emotional thinking }\end{array}$ \\
\hline 3D solid & $\begin{array}{l}\text { Internal and external walls and } \\
\text { components of product shown in } \\
\text { solid form }\end{array}$ & $\begin{array}{l}\text { Allow designer to check alignment of } \\
\text { edges. } \\
\text { Designer presents to client in order to } \\
\text { see the product in 3D. Model can be } \\
\text { rotated. }\end{array}$ \\
\hline $\begin{array}{l}\text { 3D wire frame view in } \\
\text { CAD }\end{array}$ & $\begin{array}{l}\text { Internal and external walls and } \\
\text { components of product shown such } \\
\text { that all lines are visible }\end{array}$ & $\begin{array}{l}\text { Designer moves around in space to } \\
\text { visualise where something can fit. }\end{array}$ \\
\hline Foam mock-up & Hand made foam model of artefact. & $\begin{array}{l}\text { For designers: } \\
\text { to work out various design features } \\
\text { ie: where a particular LED had to be } \\
\text { situated. } \\
\text { to overcome 'scale' problem. That is } \\
\text { the problem that designers have of } \\
\text { understanding the size of components } \\
\text { when modelling on computer. }\end{array}$ \\
\hline $\begin{array}{l}\text { Foam mock-up computer } \\
\text { generated }\end{array}$ & $\begin{array}{l}\text { CAD information used to create } \\
\text { exact representation of product. }\end{array}$ & $\begin{array}{l}\text { Created for client to enable a } \\
\text { concrete experience with the artefact: } \\
\text { allows experience that can't be found } \\
\text { in drawings, for instance, how it feels } \\
\text { in the hand. }\end{array}$ \\
\hline $\begin{array}{l}\text { SLA representation } \\
\text { (basic) }\end{array}$ & $\begin{array}{l}\text { CAD data is used to produce a } \\
\text { polymer model of the product. }\end{array}$ & $\begin{array}{l}\text { For designers to see how } 3 \text { rd party } \\
\text { components fit into the model and to } \\
\text { determine it the product can fit } \\
\text { together properly. }\end{array}$ \\
\hline $\begin{array}{l}\text { SLA painted and } \\
\text { weighted }\end{array}$ & $\begin{array}{l}\text { The SLA is sanded down and painted } \\
\text { to resemble the final product. For } \\
\text { hand held devices the SLA is } \\
\text { weighted. }\end{array}$ & $\begin{array}{l}\text { For designers: to get a feel for the } \\
\text { weight and balance of how it sits in } \\
\text { the hand. } \\
\text { For clients to fully experience the } \\
\text { product. }\end{array}$ \\
\hline
\end{tabular}




\begin{tabular}{|c|c|c|}
\hline Form & Description & Role/Actors \\
\hline Web CAD presentation & $\begin{array}{l}\text { Way of presenting final design } \\
\text { concept. Software allows client to } \\
\text { see model as it is rotated. Other } \\
\text { software allows designer to annotate } \\
\text { design in real time to highlight } \\
\text { various features. }\end{array}$ & $\begin{array}{l}\text { Used by designers with a phone hook } \\
\text { up to explain design to client. }\end{array}$ \\
\hline Power Point presentation & $\begin{array}{l}\text { Highlight design or aspects of the } \\
\text { design. }\end{array}$ & $\begin{array}{l}\text { Way to sequence and ration } \\
\text { information used for long distance } \\
\text { presentation to the client. }\end{array}$ \\
\hline Models from silicon & $\begin{array}{l}\text { Exact representation of product } \\
\text { mould made from SLA. Also } \\
\text { painted and finished. }\end{array}$ & $\begin{array}{l}\text { For client and client's sale team to } \\
\text { determine interest in product before } \\
\text { production. }\end{array}$ \\
\hline Animation & $\begin{array}{l}\text { Animation of product highlighting } \\
\text { functional aspects }\end{array}$ & $\begin{array}{l}\text { Aim to generate a desire for product. } \\
\text { Client can use to sell idea to others. } \\
\text { InDesigns can use to sell extra } \\
\text { features. }\end{array}$ \\
\hline $\begin{array}{l}\text { Quality Assurance } \\
\text { diagram }\end{array}$ & $\begin{array}{l}\text { Line drawing to emphasise one } \\
\text { critical detail. }\end{array}$ & $\begin{array}{l}\text { Used by designers to emphasis } \\
\text { critical manufacturing elements }\end{array}$ \\
\hline "The JPEG" & $\begin{array}{l}\text { Captured screen dump from CAD 3D } \\
\text { solid showing internal surface. } \\
\text { Designers then import into } \\
\text { Photoshop and annotate with arrows } \\
\text { and text. For instance: 'front boss', } \\
\text { 'back mounting plate'. }\end{array}$ & $\begin{array}{l}\text { Used to facilitate communication } \\
\text { with manufacturers. Gets around } \\
\text { 'compass' problem. That is, which } \\
\text { way is up, where the front/back is } \\
\text { located. }\end{array}$ \\
\hline
\end{tabular}

\section{DISCUSSION}

In this section three conceptualisations arising from the data analysis, presented in outline in Table 1 , are elaborated.

The first of these is the notion of views of the artefact - that different design representations focus designer attention in different ways. By examining views across different design contexts we may gain understandings that can benefit designers of new information appliances and systems. Secondly, we provide a high-level description of the industrial design process and map this process against the views. Finally, using the design process mapping, we are able to describe some of the affordances of particular design representations analysed. Again this analysis, if taken across different design contexts may offer additional understandings and tools to designers striving to meet new design challenges.

\section{Views}

Although the design of an artefact needs to be considered as a whole, different representations are required to facilitate consideration of different aspects or views of the design (Avison and Fitzgerald 1995). These aspects or views cover both the socio-cultural and the technical and embody the 'area of concern' of a design.

From observations and the examination of physical design representations the following views at InDesigns were identified: context of use, aesthetics, marketing, function, manufacturing, materials and technical. Brief descriptions of these are presented in column 1 of Table 2. The first four 
(context of use, aesthetics, marketing and function) are predominately in the realm of the sociocultural. Their concern is to enable thinking about the idea conceived to satisfy a human need or desire.

The final three (manufacturing, materials and technical) are predominately in the realm of the techno-physical concerned with materialising ideas. Although all views are considered concurrently by industrial designers, it has been observed that the emphasis shifts over time, with the sociocultural views predominating early and the more techno-physical views later in the process.

From a broader perspective, it is interesting to note that there appear to be no views that enable industrial designers to reason about the social impact of their designs. However, one designer did mention his belief that reasoning about the environmental impacts of designed artefacts will become increasingly important.

Rosenman and Gero (1998) also argue that different aspects or views represent stakeholder concerns and are implicit in the types of design representations created. Thus, it follows that views will differ depending on the design situation because of differing stakeholder concerns.

The conceptualisation of design views above is useful for two reasons. Firstly, by gaining an awareness of such views across contexts we may be able to enrich all design practice. Secondly, the view concept is useful in terms of allowing us to think about how design representations are used in the design process. This is explored in the next section.

\section{Conceive, Refine, Breakdown Cycle}

From a high level of abstraction, the industrial design process, that has been observed, can be conceptualised as a process of idea generation and refinement which is interrupted frequently.

This was observed not only for the cental design concept as a whole but also for the myriad individual ideas that make up the final design. It has been observed that an idea is conceived and refined, before an interruption leads to rethinking of the concepts. Such interruptions in the refinement process may be either intentional or unintentional, triggered by both socio-cultural and technical issues. Alternatively, they may be deliberately sought as a means of improving some aspect of a design. These interruptions can be seen to occur within views or when the integrity of a design as a whole cannot be sustained. Figure 1 depicts the notion of views and breakdowns.

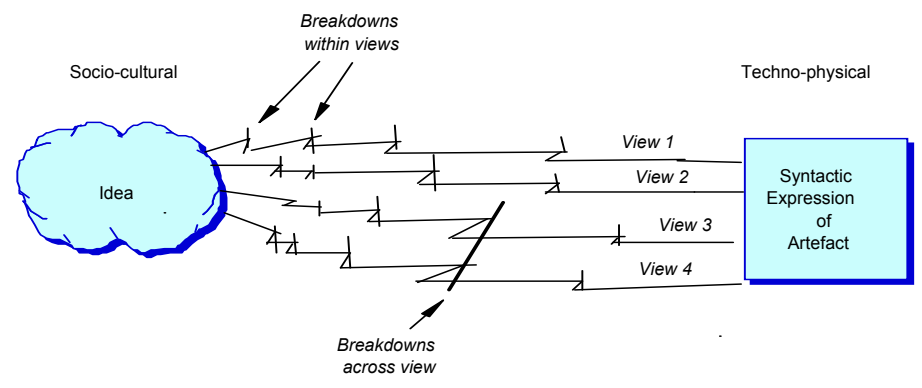

Figure 2: Breakdowns along and across views.

Different design representations were observed in use in concept generation, refinement and to trigger or understand the interruptions that occurred.

In concept generation high-level solution ideas are formulated. This involves exploration of the problem space and the generation and evaluation of various solutions all at a fairly high level of abstraction. However, sometimes discussion was observed to stall on technical issues and these were then explored in more detail.

Within the case study, concept generation was associated with a great deal of verbal discussion, 
the use of analogy and metaphor and throw-away sketches which are used to help communicate ideas or illustrate problems.

Once an idea is decided upon work then begins to refine and develop the idea. Refinement is associated with a move to more detailed, formal representations. For instance, industrial form design (the design of the product shape and styling) moves from hand sketches to computer generated illustrations. Reproducing a sketch using the more exact medium of a computer drawing package forces a refinement of the concept.

Breakdowns occur within views when there is an interruption in the flow of concept development. Such interruptions may be deliberately sought because they can be seen to improve some aspect of the design. For instance, a designer may sketch a particular aspect of the form design hoping it may trigger a slightly different (better) idea. Interruptions, along views may also occur because of sociocultural reasons, for instance becoming aware that the target market wants a 'round' aesthetic rather than a 'pointy' aesthetic, or technical reasons such as the planned manufacturing process being unavailable to meet the required time-line.

Similarly, industrial designers often use ambiguous representations as a way of opening up dialogue and eliciting design ideas from clients. Many more of these types of interruptions occur early on in the process, in the socio-cultural realm, because of the need to develop a shared meaning around the desired product.

During member checking (which involved presenting, to participants, the concepts derived from the analysis) designers confirmed the notion that they seek interruptions in pursuit of a creative leap. As one designer put it: "Interestingly you can determine how many interruptions you want to have in many ways because you can go with the path of least resistance if you want to. ....(In this case) we might not use as many tools (representations) along the process because basically a number of them might offer the interruption we don't necessarily want. (However) if you want to do something that is going to be a little more ground-breaking then you go down many paths, use many tools. This is in design, development, technical, functional, everything."

Although industrial designers focus on a particular view they are aware of the implications of their decisions on other aspects of the design. Breakdowns occur not only with representations used to focus on a particular view but because of the interconnection between views. For example, a designed product shape could not be manufactured from the originally selected material because of technical issues that were not known at the concept stage.

Breakdowns that occur when it is no longer possible to refine/develop the design idea as a whole have a far greater impact than breakdowns along a single view and these are not sought. For instance, in one observed product design, a breakdown occurred because it became apparent (through the refining process) that a particular gasket required considerable strength from the supporting structures to hold it in place. This meant that either the materials or build approach had to be re-conceptualised.

Breakdowns across views were characterized by a great deal of questioning, queries and the search for further information as well as many detailed, throw away sketches used to communicate and convince others of the problem. The breakdown stage, whether occurring along or across views led to another round of concept generation.

Table 2 below summarises the identified views, described in column 1, and the type of design representations used in concept generation and refinement. 


\begin{tabular}{|c|c|c|}
\hline View & Concept generation & Refinement \\
\hline $\begin{array}{l}\text { Context of use } \\
\text { (concerned with understanding } \\
\text { the environment the product } \\
\text { will be used in - not always } \\
\text { modelled) }\end{array}$ & $\begin{array}{l}\text { Discussions, sketches of } \\
\text { envisaged area of use (or } \\
\text { photos of existing area of use), } \\
\text { sketches of people using } \\
\text { product }\end{array}$ & $\begin{array}{l}\text { Photos or drawings of area of } \\
\text { use with drawings overlaid } \\
\text { with sketches of the product } \\
\text { and people using them. } \\
\text { Test rigs: 3D working model } \\
\text { used to test usability principles. }\end{array}$ \\
\hline $\begin{array}{l}\text { Aesthetics } \\
\text { (concerned with form and style) }\end{array}$ & $\begin{array}{l}\text { Discussions, throw away } \\
\text { sketches, sketches of various } \\
\text { foam concepts, electronics } \\
\text { printout, handmade foam } \\
\text { models, concept boards, } \\
\text { metaphors and analogy. }\end{array}$ & $\begin{array}{l}\text { Sketches of various design } \\
\text { elements, 2D computer } \\
\text { generated images, 3D } \\
\text { computer generated images } \\
\text { that can be rotated, computer } \\
\text { generated foam models }\end{array}$ \\
\hline $\begin{array}{l}\text { Marketing } \\
\text { (concerned with market } \\
\text { positioning and branding) }\end{array}$ & $\begin{array}{l}\text { Discussions, mood boards, } \\
\text { branding, metaphors, hand } \\
\text { sketches }\end{array}$ & $\begin{array}{l}\text { 2D computer generated } \\
\text { images, 3D external form, rub } \\
\text { downs (graphics), animations, } \\
\text { painted and weighted prototype }\end{array}$ \\
\hline $\begin{array}{l}\text { Functional } \\
\text { (What functions the device } \\
\text { provides - designers also think } \\
\text { about how user will interact } \\
\text { with product) }\end{array}$ & $\begin{array}{l}\text { Discussions, textual } \\
\text { descriptions, analogy }\end{array}$ & $\begin{array}{l}\text { Handmade form models, } \\
\text { sketches of aspects of the } \\
\text { design that the user will } \\
\text { interact with }\end{array}$ \\
\hline $\begin{array}{l}\text { Materials } \\
\text { (has implication for form, } \\
\text { structure, texture, manufacture) }\end{array}$ & $\begin{array}{l}\text { Discussions around the } \\
\text { properties of materials and the } \\
\text { implications for the design. }\end{array}$ & $\begin{array}{l}\text { Discussions about source, } \\
\text { availability, implications of use }\end{array}$ \\
\hline $\begin{array}{l}\text { Manufacturing } \\
\text { (concerned with how the } \\
\text { product will fit together) }\end{array}$ & $\begin{array}{l}\text { Sketches of how the product } \\
\text { will be assembled }\end{array}$ & $\begin{array}{l}\text { 2D technical drawings, QA } \\
\text { diagram, 3D CAD drawings } \\
\text { (wireframe and solid view), } \\
\text { SLA prototype }\end{array}$ \\
\hline $\begin{array}{l}\text { Technical } \\
\text { (concerned with issues such as } \\
\text { ability to withstand weather } \\
\text { conditions, shock, radio } \\
\text { frequency shielding etc) }\end{array}$ & $\begin{array}{l}\text { Discussions, textual } \\
\text { descriptions, sketches }\end{array}$ & Standard tests eg. Shock \\
\hline
\end{tabular}

Table 2: View and representations for concept development and refinement

\section{Nature and Affordances of Design Representations}

Affordances involve the interaction between an actor and the properties of an environment (Gaver 1991; Norman 1999). In the context of social interaction affordances have also been used to describe the material properties of the environment that affect how people interact (Gaver 1996) (Kreijns and Kirschner 2001). This is not to say that social behaviour cannot be accounted for in terms of 'social conventions' and 'communities of practice' but the affordance approach examines how social activities are shaped by the material environment (Gaver 1996). In the same way we can examine the extent to which the physical properties of design representations shape the design process supporting both the socio-cultural and techno-physical aspects of the design.

The case study data suggests that industrial design representations used for concept generation tend 
to be those that allow speedy generation, evaluation and exchange of ideas as well as providing high level abstractions and ambiguity. The design representations used for refinement tend to fall into two groups - throw-away representations created solely to allow the designer to work through some aspect of the design (for instance throw-away sketches and foam models) and representation that allow more formal, concrete expression of ideas (for instance hand-drawn sketches followed by 2D computer representations moving finally to $3 \mathrm{D}$ computer representations).

\section{Concept generation}

As discussed above, during concept generation high-level solution ideas are formulated. This is a very fluid part of the design process and we can conjecture that design representations should facilitate speedy generation, evaluation and exchange of ideas as well as providing high level abstractions. Ambiguity would also be useful.

The case study data suggests that design representations used for concept generation do tend to have these features. Verbal discussions and hand drawn sketches are fast and ambiguous, the use of analogy and metaphor "save lots of time in understanding what the client has in mind" (quote from designer). Concept boards feature attractive vague pictures. One designer explained it like this: "Concept boards don't have any consideration towards manufacturing, no detail, they are very ambiguous. They just look nice. They have no detail. See this shape here, that could be a cut, it could be a different material, a different colour. At the moment it is just a shape." The advantage of this ambiguity is that it fosters communication and requirement elicitation. The same designer explained it as follows: "We can then ask questions like: "What do you think if that was a different material?'; 'What do you think if that was a sticker?'; 'Do you like the fact that it is a different colour or do you think it should be all the same colour?'. So it is just a talking point. We will throw in some different ideas."

\section{Refinement}

Refinement is associated with a move to more detailed, formal representations.

This part of the design process requires thinking through issues so high-level concepts can be made more concrete. We can conjecture that design representations need to facilitate designer thinking, and to enable more detail to be added.

An analysis of the case study data suggest that design representations used for refinement do tend to fall into two groups - throw-away representations created solely to allow the designer to work through some aspect of the design and representations that allow more formal, concrete expression of ideas.

For example, to help him think through an issue such as where a cord would come out of a product one of the designers used many sketches focussing on just that feature. In other situations, a designer may create a foam model by hand to help think through an issue. One designer described the reason he decided to make a foam model while he was trying to refine a design in modelling software. "This (the foam model) was built for me to get my head around how big it is because after building it yesterday in ProDesigner (software package) I thought it looked pretty big, pretty bulky, the size looked awkward, so I built up this model this morning and it doesn't seem as big as I thought". The foam model provides the designer with something a computer-generated image can not. As this designer went on to explain: "The one thing that might be hard to understand on the screen is the physical size, because you can be working right in close and you get totally disoriented by the scale, although you know its dimensions. It is really hard to understand scale until you get a prototype back or make a foam model."

The goal in refining an idea is to bring it closer to a formal syntactic representation. There will be a number of representations used along this road. In form design for instance, a designer begins with 
hand-drawn sketches and as the next stage reproduces them as a $2 \mathrm{D}$ image in software. Because the computer software is more exact than a hand sketch designers explained that it allows a first cut at refining the form concept. Designers explained this in terms of: "it allows more detail, you can get it looking quite realistic"; "it gives more of a concrete idea"; "(it is) better to explain things like outlines, colours and materials." The next stage of refinement for form design comes with the move to modelling the concept as a $3 \mathrm{D}$ surface drawing.

\section{Breakdown}

Breakdowns occur within views when there is an interruption in the flow of concept development. These interruptions may be sought as a means of improving understanding. Interruptions along views may also occur because of socio-cultural or technical reasons.

Breakdowns were observed to also occur when it was no longer possible to refine/develop the design idea as a whole. These types of breakdowns are not sought and in the case study were often flagged by a 'salient detail' - one detail that could not be worked around and led to the need to reconceptualise part of the design.

Breakdowns across views occur because it is not possible to understand all the issues at the conceptual design stage. For instance, in one product design the Light Emitting Diodes (LEDs), for aesthetic purposes, where not situated above the position of the LEDs on the printed circuit board (PCB). This is not unusual and in the design light pipes were used to bring the light from the PCB to the surface. However, it was not until testing that radio frequency leakage around the light pipes was discovered to be an issue. This technical issue lead to a breakdown that required the form design to be reworked.

Representations used around breakdowns included those that allowed communication of the problem in a convincing way as well as representations that allow analysis and discussion. Representations included detailed sketches backed up by verbal discussions and often supported by textual explanations.

Characteristics of representations studied

To summarise then, some of the characteristics of design representations noted were: speed of creation and change, level of abstraction and detail, amount of ambiguity and degree of context provided. Other important characteristics of the design representations included: the ability of the representation to depict the physical size and feel of the intended artefact, the ability of the representation to enable reasoning about 'the compass problem', that is which way is up, down, front and back and the ability of the representation to elicit a positive emotional response from the client.

\section{IMPLICATIONS FOR IS DESIGN - SOME INITIAL COMMENTS}

As previously indicated, the present research seeks to build an enhanced understanding of the nature and affordances of representations in the design process and to argue the need for information systems as a discipline to open up discussion of the design representations required to effectively design systems that might be required for the next generation of ubiquitous IS applications.

An initial case study has been reported, drawing upon the world of industrial design as a means of exposing a rich selection of design artefacts employed in a short life-cycle development - features that might inform an enhanced understanding of IS design as it faces increasingly novel design issues and shortening development times.

The analysis reported above has highlighted:

- A rich classification of views of the artefacts;

- An industrial design conceive, refine, and breakdown cycle, both within and 
across views; and

- An interpretation of the application of design artefacts at various stages of the design cycle in terms of the nature of affordances.

The implication of these emerging understandings for design in the IS context remains. Suffice to observe that the notion of a "catastrophe cycle", possibly analogous to breakdown, has been observed in Information Systems design (Nguyen et al. 2000). Further, recent work in creativity and the IS requirements engineering process (Cybulski et al. 2003) has highlighted, the importance of creative insight in the conceptualisation of information systems - a process that may well be enhanced by further investigations of the notions of views and affordances of design representations opened up by the case study reported in this work.

Further studies in other contexts will follow this case-study, in particular contexts that facilitate understanding of if and how the insights gained from this first case study might translate to designing for the world of ubiquitous computing. From this we hope to develop a framework that will enable the links between the various characteristics of design representations to be drawn together. Having such a framework for understanding the nature and affordances of design representations would provide a basis for investigating which representations are most effective to tackle specific design tasks.

\section{CONCLUSIONS}

Design is a complex human activity that requires consideration of both socio-cultural and technical issues. Design representations are instrumental in the process of moving from an artefact idea to embodiment in the techno-physical realm. The socio-cultural realm, because it exists only as 'human concepts and interpretations' (Rosenman and Gero 1998), is where we can conjecture that there may be a great deal that different design disciplines can offer each other especially as we design for mobile, wearable, tangible and ubiquitous computing that radically alters the context of traditional information systems. This will require an expansion of our notions of the 'area of concern' that design must consider.

Many researchers are attempting to uncover the design issues in these new areas (see for example (Dix 2000); (McNeese 2003; York and Pendharkar 2004)). What is also required is an understanding of the nature and affordances of the design representations that will be required to enable reasoning in these new areas. As Benyon (2002) puts it "the concepts and representations that we need for designing such experiences may take us a long way from where we are now."

\section{REFERENCES}

Avison, D.E, and G. Fitzgerald. 1995. Information Systems Development: Methodologies, Techniques and Tools. Berkshire, UK: McGraw-Hill International (UK) Limited.

Babbie, E. 2001. The Practice of Social Research. Belmont, CA.: Wadsworth.

Benyon, D. 2002. "Representations in Human-Computer Systems Development." Cognition, Technology and Work 4: 180 - 196.

Brereton, M. 2004. "Distributed Cognition in Engineering Design: Negotiating between Abstract and Material Representations." Pp. 83-103 in Design Representation: Springer-Verlag London Limited.

Carroll, J, S Howard, F Vetere, J Peck, and J Murphy. 2001. "Identity, Power and Fragmentation in Cyberspace: Technology Appropriation by Young People." Pp. 95-102 in Twelfth Australasian Conference on Information Systems. Coffs Harbour, NSW Australia. Chen, P.P.S. 1976. "The Entity-Relationship Model: Toward a Unified View." ACM Transactions 
on Database Systems 1: 9-36.

Cybulski, J., L. Nguyen, T. Thanasankit, and S. Lichtenstein. 2003. "Understanding Problem Solving in Requirements Engineering: Debating Creativity with IS Practitioners." in Pacific Asia Conference on Information Systems.

Dix, A. 2000. "Exploiting Space and Location as a Design Framework for Interactive Mobile Systems." ACM Transaction on Computer-Human Interaction 7: 285-321.

Dym, C.L. 1994. Engineering Design: a synthesis of views. Cambridge, UK: Cambridge Univerty Press.

Faro, A., and D. Giordano. 1999. "Ontology, aesthetics and creativity at the crossroad in Information System design." Pp. 124-131 in Creativity and Cognition. Loughborough UK.

Galle, P. 1999. "Design as intentional action: a conceptual analysis." Design Studies: 57-81.

Gaver, W. W. 1991. "Technology Affordances." Pp. 79-84 in CHI'91. New Orleans, Lousiana: ACM, New York.

Gaver, W. 1996. "Affordances for interaction: the social is material for design." Interactions 8: 111129.

Hevner, Alan R., Salvatore T. March, Jinsoo Park, and Sudha Ram. 2004. "Design Science in Information Systems Research." MIS Quarterly 28: 75-105.

Klein, H.K., and M. Myers. 1999. "A Set of Principles for Conducting and Evaluating Interpretive Field Studies in Information Systems." MIS Quarterly 23: 67-94.

Kreijns, K., and P.A. Kirschner. 2001. "The Social Affordances of Computer-Supported Collaborative Learning Environments." Pp. T1F-12 to T1F-17 in 31st ASEE/IEEE Frontiers in Education Conference. Reno, NV: IEEE.

Kyng, M. 1995. "Making Representations Work." Communications of the ACM 58: 46-55.

Marshall, C., and G. B. Rossman. 1995. Designing Qualitative Research. Thousand Oaks, CA.: SAGE Publications.

McNeese, M.D. 2003. "New visions of human-computer interaction: making affect compute." International Journal of Human-Computer Studies 59: 33-53.

Miles, M. B., and A. M. Huberman. 1994. Qualitative Data Analysis: an expanded sourcebook. California, USA: SAGE Publications.

Nguyen, L., J. Carroll, and P. Swatman. 2000. "Supporting and Monitoring the Creativity of IS Personnel during the Requirements Engineering Process." Pp. 1-9 in Proceedings of the 33rd Annual Hawaii International Conference on System Sciences, Institute of Electrical and Electronics Engineers. Hawaii, USA.

Norman, D.A. 1999. "Affordance, Conventions, and Design." Interactions May + June: 38-42.

Perry, M., and D. Sanderson. 1998. "Coordinating joint design work: the role of communication and artefacts." Design Studies 19: 273-288.

Rosenman, M.A., and J.S. Gero. 1998. "Purpose and function in design: from the socio-cultural to the techno-physical." Design Studies: 161-186.

Saddler, Harry. 2001. "Understanding Design Representations." Interactions July + Aug: 17-24.

Simon, H.A. 1996. The Sciences of the Artifical. Cambridge, MA: MIT Press.

Stolterman, E. 1999. "The design of information systems: parti, formats and sketching." Information Systems Journal 9: 3-20.

Suchman, L. 1994. "Preface." in Hawaii International Conference on Systems Sciences. Hawaii, USA.

York, J., and P. C. Pendharkar. 2004. "Human-computer interaction issues for mobile computing in a variable work context." International Journal of Human-Computer Studies Article in press, corrected proof. 


\section{COPYRIGHT}

The following copyright statement with appropriate authors' names must be included at the end of the paper

[Susan Keller, Ross Smith, Steve Howard, Jennie Carroll] (C) 2004. The authors assign to ACIS and educational and non-profit institutions a non-exclusive licence to use this document for personal use and in courses of instruction provided that the article is used in full and this copyright statement is reproduced. The authors also grant a non-exclusive licence to ACIS to publish this document in full in the Conference Papers and Proceedings. Those documents may be published on the World Wide Web, CD-ROM, in printed form, and on mirror sites on the World Wide Web. Any other usage is prohibited without the express permission of the authors. 